\title{
Medievalista
}

Online

$20 \mid 2016$

Número 20

\section{Governar a cidade e servir o rei. A oligarquia concelhia de Évora em tempos medievais}

\section{(1367-1433)}

Tese de Doutoramento em História apresentada à Universidade de Évora, Janeiro de 2016. Orientação da Professora Doutora Hermínia Vilar

\section{Joaquim Bastos Serra}

\section{(2) OpenEdition}

\section{Journals}

Edição electrónica

URL: http://journals.openedition.org/medievalista/1231

DOI: 10.4000/medievalista.1231

ISSN: 1646-740X

\section{Editora}

Instituto de Estudos Medievais - FCSH-UNL

\section{Refêrencia eletrónica}

Joaquim Bastos Serra, " Governar a cidade e servir o rei. A oligarquia concelhia de Évora em tempos medievais (1367-1433) », Medievalista [Online], 20 | 2016, posto online no dia 01 dezembro 2016, consultado o 23 setembro 2020. URL : http://journals.openedition.org/medievalista/1231 ; DOI https://doi.org/10.4000/medievalista.1231 
Título / Title: Governar a cidade e servir o rei. A oligarquia concelhia de Évora em tempos medievais (1367-1433)

Tese de Doutoramento em História apresentada à Universidade de Évora, Janeiro de 2016.

Orientação da Professora Doutora Hermínia Vilar

Autor(es) / Author(s): Joaquim Bastos Serra

Universidade / University: Universidade de Évora

Faculdade e Departamento / Unidade de Investigação - Faculty and Department /

Research Center: Centro Interdisciplinar de História, Culturas e Sociedades

Código Postal / Postcode: 7000-809

Cidade / City: Évora

País / Country: Portugal

Email: jbserra@uevora.pt

Fonte: Medievalista [Em linha]. Direc. Bernardo Vasconcelos e Sousa. Lisboa: IEM.

Disponível em:

http://www2.fcsh.unl.pt/iem/medievalista/MEDIEVALISTA20/serra2010.html

ISSN: 1646-740X

Data de recepção do texto / Received for publication: 27 de Maio de 2016 


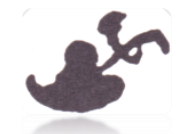

\section{Apresentação de tese / Thesis presentation:}

\section{Governar a cidade e servir o rei. A oligarquia concelhia de Évora em tempos medievais (1367-1433)}

Tese de Doutoramento em História, apresentada à Universidade de Évora, Janeiro de 2016. Orientação da Professora Doutora Hermínia Vilar

Joaquim Bastos Serra

A tese tem como fulcro o estudo do grupo ligado à administração municipal da cidade de Évora, no período compreendido entre 1367-1433. Procurou-se caraterizar socialmente esse grupo e analisar as suas estratégias de manutenção e de reprodução do poder, avaliando-se, em paralelo, o peso e a importância que o controlo dos cargos municipais assumia nas suas lógicas de afirmação, no contexto da cronologia escolhida.

O trabalho em causa pretende, assim, ser um contributo para o aprofundamento do tema das oligarquias municipais portuguesas na Idade Média, as quais continuam, ainda, a ser pouco conhecidas, apesar dos estudos já existentes. De facto, os dirigentes municipais ficaram um pouco à margem do surto prosopográfico que, nas últimas décadas, foi revelando os quadros sociológicos das instituições. Esse tipo de estudos centrou-se, sobretudo, no Desembargo Régio e nas instituições religiosas, só lateralmente chegando às administrações municipais. Com efeito, para além do estudo de Adelaide Costa sobre as vereações e os vereadores do Porto e do trabalho de Mário Farelo sobre a oligarquia concelhia de Lisboa, existem apenas artigos pontuais sobre os dirigentes de alguns municípios, como é o caso de Loulé, Ponte de Lima, Vila do Conde e outros, assim como referências genéricas à administração municipal em estudos monográficos sobre vilas e cidades. Muito falta ainda saber sobre as realidades sociológicas das administrações concelhias concretas, para o período medieval. Não se estranha, por isso, que seja ainda hoje difícil levar a cabo estudos comparativos sobre os grupos dirigentes 
municipais para a realidade portuguesa. As razões que justificam um tal estado de coisas serão, decerto, de natureza diversa, mas não deixam de se prender com as próprias características da documentação municipal que chegou até nós. Como se sabe, esta é, de um modo geral, bastante fragmentada e muito dispersa, tornando difícil acompanhar percursos e reconstituir os grupos dirigentes, sendo que, em muitos casos, a informação disponível nem sequer permite identificar os elencos camarários com níveis mínimos de sequencialidade.

Muito embora nos tivéssemos debatido com o mesmo tipo de problemas, a documentação eborense, pelo seu volume e qualidade, permitiu-nos equacionar a possibilidade de levar por diante um estudo desta natureza. Para além da riqueza dos arquivos das diversas instituições da cidade, onde foi possível recolher dados preciosos sobre os homens e as famílias ligadas à governação, Évora possui uma documentação municipal de algum significado, que conta com fontes de inegável valor. É o caso, nomeadamente, d’O Livro das Posturas Antigas - que, apesar dos múltiplos problemas de datação que coloca, nos deixa imensa informação sobre o que podemos designar de poder municipal em exercício -, dos inventários do arquivo e dos bens municipais, bem como do Regimento da cidade de Évora. Este é um documento único para o panorama nacional, em que se sistematizam os cargos e as funções e se traça um quadro de situação da administração municipal da cidade num dado momento. Muito embora a informação que chegou até nós esteja longe daquela que gostaríamos de ter, o aproveitamento exaustivo dos dados e a sua sistematização, a partir dos métodos prosopográficos, tornou possível realizar uma caraterização sociológica minimamente consistente do grupo que dirigiu os destinos eborenses.

Importa vincar que o estudo beneficiou também do facto de a realidade da cidade e das suas instituições ser, hoje, relativamente bem conhecida, fruto da diversidade e da qualidade dos estudos que se têm debruçado sobre a urbe no período medieval. Entre outros, importa destacar, pela importância que assumiram para o nosso estudo, os trabalhos de Ângela Beirante, a quem se deve o estudo de fundo sobre a cidade nos tempos medievos, complementado com uma multiplicidade de artigos de grande interesse. De relevo, para a problemática em causa, são também os trabalhos de Hermínia Vilar, historiadora que se debruçou sobre a diocese eborense e o seu quadro 
humano, na sua dissertação de doutoramento, que teve, para nós, grande utilidade pela interligação que existia entre as elites municipais e as eclesiásticas. Esta autora tem vindo também a fazer múltiplas reflexões sobre as elites locais eborenses em comunicações e artigos que são incontornáveis quando abordamos as questões relativas aos dirigentes municipais da cidade. Aos estudos já referidos, podemos acrescentar a tese de doutoramento de Filipa Roldão sobre o arquivo municipal de Évora e as suas formas de organização. É justo referir, ainda, a importância que o Projeto Elites locais $e$ redes clientelares, desenvolvido pelo CIDEHUS-UÉ, no início deste século, assumiu, quer na definição dos conceitos e das problemáticas relativos ao estudo das elites locais, quer no afinar das metodologias mais adequadas para levar a bom porto investigações que são, pela natureza do seu objeto, algo fugidias e complexas.

Como diversos autores têm vindo a chamar à atenção, e o nosso estudo comprova, não é possível estudar as oligarquias e os dirigentes municipais de forma isolada face aos respetivos contextos urbanos. De facto, os indivíduos e os grupos de parentesco ligados à governação não cingiam o seu protagonismo ao concelho. As suas estratégias de afirmação e promoção passavam pelo controlo das diversas instituições da cidade e até pelo aproveitamento das suas dinâmicas económicas, pelo que só por via do cruzamento de informação de origem e natureza diversa se pode levar por diante o desiderato de caraterizar a oligarquia e compreender as suas lógicas de controlo e de reprodução do poder.

Face ao conjunto de questões que colocámos, talvez vasto, mas que considerámos essencial para podermos caraterizar o grupo em causa, optámos por definir um tempo de análise curto, já que nos pareceu difícil abarcar todas estas dimensões em cronologias mais amplas. Esta opção por uma cronologia menos alargada do que aquela que comummente tem sido utilizada em estudos análogos, não deixa naturalmente de conter algumas limitações e mesmo alguns riscos. Não permite captar dinâmicas mais dilatadas, mas tem, quanto a nós, a vantagem de possibilitar um maior aprofundamento e uma maior contextualização da análise.

A opção cronológica acabou por recair no período de cerca de sete décadas correspondente aos reinados de D. Fernando e de D. João I, passando pela crise 
dinástica. Para além dos fatores que se prendem com as caraterísticas da documentação que possuímos para esse período, a escolha partiu também da constatação de que não eram muitos os estudos existentes sobre as elites locais, para essa cronologia. Uma constatação que não deixa de causar alguma perplexidade, tendo em atenção que vulgarmente se atribui um papel relevante às elites urbanas em todo o processo conducente à subida ao poder da dinastia de Avis.

O caso de Évora, pelo relevo que a cidade assumiu, por esses anos, e pelo envolvimento da sua elite dirigente no curso dos acontecimentos, pareceu-nos ser um bom ensejo para revisitar o tema, contribuindo para o melhor conhecimento dessas problemáticas, nomeadamente avaliando o impacto que os acontecimentos finais do reinado fernandino e a mudança dinástica tiveram nas dinâmicas concelhias e particularmente no seu grupo dirigente. De qualquer modo, e importa deixar claro esse aspeto, o estudo que levámos a cabo não é especificamente sobre a crise, nem sobre as razões que terão levado as principais famílias ligadas à governação eborense a aderir de uma forma clara e empenhada à causa do mestre de Avis. Essa seria, sem dúvida, uma questão do maior interesse, mas que, a ser desenvolvida, nos levaria para longe dos nossos propósitos. Limitámo-nos, assim, a identificar o posicionamento dos principais grupos familiares face às opções políticas em confronto, tentando ajuizar das consequências que essas tomadas de posição tiveram sob o ponto de vista das suas trajetórias. Foi essencialmente com esse intuito que, no primeiro capítulo do nosso estudo, um capítulo de contextualização, designado de $O$ rei, a cidade e o Concelho, pusemos em relevo o papel dos nossos homens nos acontecimentos marcantes desse período.

Vale a pena referir que muitos dos indivíduos e famílias ligados à governação tiveram um papel ativo em muitos dos processos que ocorreram entre o final do reinado fernandino e a consolidação da nova dinastia. Envolveram-se nos conflitos bélicos, sobretudo nos que tiveram lugar na Comarca, no âmbito da designada "terceira guerra fernandina". Após a morte de D. Fernando, e quando se colocou a questão da sucessão, abraçaram de forma desassombrada a causa do mestre de Avis, tendo assumido um papel preponderante na consolidação desse projeto político. Orientaram as revoltas populares que rebentaram na cidade, mobilizaram a sociedade política local e reuniram recursos materiais e financeiros que colocaram ao serviço do Mestre. Fazendo uso da 
sua experiência militar, forjada nos campos de batalha das guerras fernandinas, participaram ativamente nas ações militares que se estenderam muito para além de Aljubarrota, onde, aliás, diversos membros das famílias eborenses ligadas à governação estiveram presentes. Um envolvimento que teve múltiplas consequências pessoais e sociais, que o estudo procura identificar.

Deve dizer-se que, muito embora o tema central da dissertação sejam os homens e as suas estratégias de poder, o estudo, como não poderia deixar de ser, demora-se também na própria administração concelhia e nas dinâmicas que foi sofrendo durante este período. Como se compreende, seria difícil ajuizar sobre os diferentes níveis de poder que existiam no interior do círculo governativo, sobre as carreiras e sobre o ascendente que estes homens alcançaram na cidade, sem atentar no perfil dos cargos que exerceram. Tendo em atenção as vicissitudes que marcaram estas décadas, onde se conta uma mudança dinástica, considerou-se pertinente pôr em relevo as próprias transformações que a orgânica concelhia foi sofrendo, ao longo destas décadas, procurando explicar as linhas de evolução do seu devir. Por isso, no segundo capítulo do estudo, designado precisamente de A orgânica concelhia - Principais cargos $e$ funções, procurámos captar os múltiplos ajustamentos de que a administração municipal eborense foi sendo objeto, estabelecendo comparações com outras realidades portuguesas, sobretudo, com as maiores cidades, como Lisboa e o Porto, com as quais Évora se equivalia.

No que diz respeito à orgânica da administração concelhia, a questão dos regedores foi um dos tópicos a que dedicámos maior atenção. Cargo que surge na cidade nos anos setenta e oitenta de trezentos e que voltamos a encontrar nos anos vinte e nos inícios dos anos trinta da centúria seguinte. Trata-se, como se sabe, de um cargo que surgiu em diversos concelhos, no final do período fernandino, sobre o qual, ainda, pouco se conhece. A par de Lisboa, Évora foi um dos núcleos urbanos onde os regedores ganharam maior relevo, sendo que na cidade transtagana eles terão perdurado bem para além do que se verificou em Lisboa. O caso de Évora traz alguns esclarecimentos sobre o contexto e os objetivos que terão estado na origem da criação dos regedores. Um cargo que, pelo facto de ser de nomeação régia e não se encontrar sujeito às regras da 
rotatividade anual, alterava significativamente os moldes em que, até aí, o poder municipal se encontrava organizado.

Ao contrário do que até agora tem sido aceite como um dado adquirido, supomos que os regedores não terão sido uma realidade continuada, em Évora, entre os anos setenta de trezentos e o início da década de trinta da centúria seguinte. Tanto mais que, entre cerca de 1385 e 1420, não temos nenhuma referência objetiva ao cargo. Apesar de ser possível que a ausência de referência às funções possa apenas decorrer dos acasos da preservação documental, estamos em crer que, nos anos que se seguem à subida ao poder do monarca de Avis, o cargo se terá extinguido ou, pelo menos, terá perdido relevância na cidade, sendo apenas reativado num período posterior. Nomeadamente nos anos vinte de quatrocentos, no quadro de uma profunda intervenção régia na cidade, que deu origem à publicação do Regimento da cidade de Évora. O estudo tenta compreender as razões que terão justificado a nomeação de regedores em cada um destes momentos.

No período fernandino, a nomeação dos regedores surge num quadro geral de desestabilização da vida do reino e da cidade, onde muitos sinais deixam adivinhar um clima de profunda crise. A sua nomeação, por parte da Coroa, teve como propósito a procura de estabilização da administração e sobretudo a fidelização à coroa de um concelho que se mostrava estrategicamente relevante nesse quadro político e militar. A reativação dos regedores, nos anos vinte de quatrocentos, corresponde a um contexto com caraterísticas diversas do anterior. O Regimento da cidade, elaborado pelo corregedor João Mendes de Góis, homem forte do desembargo, é bem o espelho do ímpeto regulador da coroa e da superior capacidade de intervir de forma estruturada na administração municipal. Relembremos que datam também desses anos, num período de associação de D. Duarte à governação, outras propostas algo inovadoras, como é o caso do Regimento dos Corregedores e do Regimento dos Coudéis, a que se encontra ligado o mesmo oficial do desembargo, que esteve por detrás do regimento eborense. Independentemente das possíveis disfuncionalidades que o corregedor possa ter detetado na administração da cidade, supomos que é dentro desse mesmo espírito reformista que se deve entender a tentativa de reativação dos regedores. Évora, pela proximidade à coroa e pela relevância que assumia no quadro do reino, surge-nos, 
sobretudo, como um campo de ensaio de uma proposta que talvez se tivesse pensado alargar a outros concelhos.

A tentativa de imposição dos regedores deixa claro que a Coroa, pelo menos em determinados momentos, colocou em cima da mesa a possibilidade de alteração do modelo de organização do poder municipal, influenciado talvez pelo sucesso que os regidores castelhanos, criados pelo Regimiento, iam assumindo no reino vizinho. Tendo em atenção as funções que lhe estavam adscritas, é provável que se tivesse equacionado a possibilidade de proceder à substituição dos vereadores por regedores nomeados pelo rei. Uma tentativa que, como sabemos, não passou disso mesmo, já que os regedores acabaram por não vingar. Tal verificou-se, muito provavelmente, por pressão dos próprios concelhos que, como demonstram alguns capítulos de corte, não viam com bons olhos a perda da possibilidade de escolha de um oficial concelhio que se revelava vital na gestão dos quotidianos urbanos e que, para além do mais, se encontrava já bastante enraizado e consolidado na orgânica dos governos municipais.

De qualquer modo, apesar de a sua vigência ter sido limitada, a nomeação de regedores, pelo menos em Évora, não deixou de ter reflexos nas próprias dinâmicas internas do grupo dirigente, fortalecendo o peso do monarca no concelho por via da promoção daqueles que lhe eram próximos e em quem depositava confiança. Os regedores acabaram, assim, por contribuir para a criação de uma administração mais próxima e mesmo mais dependente da coroa. A indicação para o cargo teve também, como seria de esperar, reflexos nas carreiras concelhias dos nomeados que, por não estarem sujeitos às regras da rotatividade exigida pelos processos eleitorais, surgem de forma regular ligados à administração, em alguns casos acumulando as funções de Regedor com as de juízes concelhios.

Esta matéria remete-nos para uma outra questão que nos ocupou: a das carreiras concelhias, que deu origem a um outro capítulo, o terceiro, designado por Percursos na administração. A reconstituição dos elencos camarários que levámos a cabo, só possível para alguns anos, permitiu-nos, ainda assim, identificar 178 indivíduos que, nessas décadas, desempenharam funções governativas na cidade. Muito embora correspondam apenas a uma parte do total de homens que, nesse período, terão passado pela 
governação, a sua representatividade acaba por ser superior àquela que, numa primeira análise, se poderia supor, já que muitos deles desempenharam funções por diversas vezes. Em conjunto, estes homens terão ocupado cerca de metade dos lugares que durante estes anos foram preenchidos por via dos processos eleitorais, o que nos dá, desde logo, uma ideia dos elevados níveis de rotatividade dos indivíduos em funções governativas. Para cada um desses indivíduos foi elaborada uma notícia biográfica, em que se podem captar os seus percursos e os seus quadros de relações.

Deve dizer-se que o delinear das carreiras concelhias não se revelou tarefa fácil, tendo sido necessário definir critérios de compreensão das mesmas, até porque, ao contrário do que se passava nas carreiras burocráticas, como as do Desembargo Régio, por exemplo, não estamos face a percursos contínuos. A entrada dos homens nos elencos camarários estava, como é conhecido, sujeita às regras da rotatividade e de processos eleitorais que podiam afastar um indivíduo de funções governativas efetivas por mais ou menos tempo. Para além desta questão, foi necessário contornar os óbices colocados pelos vazios documentais e os acasos da preservação documental que podem distorcer o acompanhamento dos percursos na administração.

Não nos limitámos, por isso, a avaliar as carreiras exclusivamente a partir do desempenho de funções eletivas. Juntámos-lhe outros indicadores que permitissem também ter uma noção do grau de ligação ao poder municipal. Contabilizámos as presenças dos indivíduos nas reuniões de vereação, mesmo quando não desempenhavam funções efetivas, já que, face ao carácter restrito que assumiam, elas revelam sempre proximidade face ao poder municipal e capacidade de influência. Atentámos também noutras funções que os indivíduos foram desempenhando ao serviço do município, por exemplo, a procuração às Cortes ou a presença em outros atos de representação e em missões específicas. Por último, levámos em consideração o tempo médio de ligação ao concelho, contabilizado entre a primeira e a última referência em atos realizados pela edilidade.

A leitura dos dados, a partir destes critérios, permitiu-nos reagrupar as carreiras, identificando diferentes níveis de envolvimento com a administração municipal. Apesar da rotatividade, constata-se a existência de um núcleo duro de indivíduos que - de 
forma regular - acompanhavam a administração e que foram enquadrando aqueles que, digamos, de forma mais pontual ocupavam os lugares. Refira-se que os níveis de abertura do grupo dirigente eram apenas aparentes, até porque estamos face a processos eleitorais indiretos. Daí que, em muitos casos, mesmo os menos implicados com a governação efetiva, e que só esporadicamente passavam pelos cargos, se encontrassem também, de uma ou de outra maneira, ligados aos homens ou famílias fortes da governação.

De facto, mais dos que as competências, os perfis individuais ou a formação, o que verdadeiramente contava na estruturação das carreiras concelhias era, sobretudo, como fomos demonstrando, o grau de implicação que os indivíduos mantinham com os que já estavam instalados no poder. Realidade que, na prática, colocava o poder municipal nas mãos de um número restrito de famílias. O levantamento dos laços familiares e clientelares dos que passaram pelos cargos deixou evidente o peso que o parentesco assumia na estruturação das carreiras.

Tendo em atenção essas lógicas, não se estranha que fosse comum a presença, em simultâneo ou de forma sequencial, de diversos membros de um mesmo grupo familiar na governação, caso de irmãos, tios e sobrinhos, primos, a que se juntam os que lhes estavam ligados por laços de natureza clientelar. Ainda que não se verificasse uma patrimonialização institucionalizada dos ofícios, não deixava de existir uma quase hereditariedade de funções, traduzida numa substituição geracional de pais/filhos/netos/bisnetos que criou verdadeiras dinastias municipais. Há ainda a realçar que, nesta substituição geracional, os descendentes tendiam a ocupar os mesmos cargos dos seus antecessores. Neste mundo fechado e hierarquizado, havia pouco espaço a rasgos individuais e à realização de cursus honorum concelhios. O lugar que cada um tinha na governação não estava, para a grande maioria, ligado ao percurso que se ia fazendo na administração. Dependia, essencialmente, do capital social e do peso que o grupo a que se pertencia tinha no seio do círculo governativo.

A análise das carreiras, se deixou evidente o forte grau de oligarquização que vigorava na administração municipal eborense, revelou também a existência de diferentes níveis 
de prestígio e de poder entre os que exerciam os cargos e que estavam longe de constituir um grupo socialmente homogéneo.

Note-se que, para além desse quadro de relações estabelecidas no círculo fechado da governação, foi ficando também clara a vinculação que estes homens mantinham com outros níveis de poder, estruturados a partir da cidade, ou mesmo com a Coroa e os círculos régios, que se assumirão progressivamente como fulcrais nas suas trajetórias. A investigação permitiu identificar, entre os governantes, gente ligada por via clientelar a uma nobreza de maior estatuto instalada, ou com fortes ligações à cidade, como é o caso dos Melo e dos Castro, mas sobretudo ao monarca e aos círculos régios.

Importa realçar que o peso do poder régio é um aspeto estruturante da vida da administração municipal no período de que nos ocupámos. Muito embora o peso da Coroa fosse um traço comum da vida concelhia das vilas e cidades do reino, ele ganhou um especial significado em núcleos urbanos próximos da corte. Mário Farelo demonstrou-o para Lisboa. O nosso estudo confirma-o também para Évora. Lembremos que nos anos de fogo das guerras fernandinas, bem como nos da crise e nos que se lhe seguiram, que foram ainda de instabilidade e de ameaça, Évora assumiu uma forte importância estratégica e político-militar, tendo conhecido, nas décadas seguintes, uma crescente projeção no quadro do reino que, definitivamente, fez dela um dos eixos de permanência da corte.

A projeção da cidade teve naturais reflexos na vida concelhia, não apenas no andamento da administração, mas na própria configuração e nos horizontes sociais do grupo dirigente. A proximidade da corte, que por vezes permanecia por largos meses na cidade, colocou o município e a sua administração sob o olhar atento da Coroa, que não se inibiu de levar a cabo intervenções em alguns casos de grande profundidade. Se, nos tempos fernandinos, a intervenção dos funcionários régios, na cidade, era já significativa, assistindo-se à intervenção de corregedores e juízes régios em diversos aspetos da governação corrente, como o Livro das Posturas Antigas tão bem testemunha, nos anos finais do reinado joanino essas intervenções assumem um carácter mais sistémico e profundo. O Regimento da Cidade de Évora, publicado por volta dos anos vinte de quatrocentos, é bastante esclarecedor a esse nível. Partindo da análise 
sistemática dos aspetos disfuncionais, o corregedor da corte propõe uma reorganização profunda da administração e uma clarificação das competências e funções dos diversos intervenientes na complexa tarefa de gerir a cidade.

Refira-se que a própria nomeação dos regedores e o protagonismo que tiveram em Évora não se podem desligar da relevância que a cidade assumia para a Coroa, havendo ainda que considerar que a sua nomeação, como já vimos, contribuiu para o reforço das fidelizações ao monarca. A par desses fatores há ainda que contar com os efeitos das opções políticas, no quadro da crise dinástica, que reforçou a posição daqueles que estiveram do lado vencedor. O caso mais paradigmático é o dos Lobo, que tiveram um enorme ascendente na administração nas décadas seguintes à subida ao poder do monarca de Avis. A ele juntam-se os d'Arca, os Fuseiro, os Carvoeiro, entre outros.

Face ao exposto, não causa estranheza que, sobretudo nos anos do após crise, o concelho surja enxameado de escudeiros, criados e vassalos régios, sendo também comum a presença de gente ligada a personagens da Corte e do Desembargo. Aos membros das famílias mais tradicionalmente ligadas à administração concelhia, como os Lobo, os Pestana, os Façanha, os Carvoeiro, juntaram-se indivíduos oriundos de famílias que se movimentavam no entorno régio. Trata-se maioritariamente de ramos secundários do que, à falta de melhor definição, podemos designar de uma pequena nobreza de serviço, que se instala ou se aproxima da cidade e da sua governação. É o caso dos Brito, dos Fonseca, dos Cerveira, dos Abreu, dos Pimentel e de outros que, com maior ou menor regularidade, surgem também nos cargos municipais. No final da nossa cronologia, a oligarquia eborense era ainda mais próxima, mais fidelizada e mais sintonizada com o monarca.

É no quadro de uma cidade cortesã e num contexto de alguma excepcionalidade, que favoreceu processos de rápida mobilidade social, que se devem entender as estratégias de afirmação e de consolidação das posições sociais seguidas pelos grupos familiares ligados à governação.

O quarto e último capítulo do nosso trabalho, intitulado de Estratégias de promoção e de consolidação das posições sociais, debruça-se precisamente sobre as lógicas, as 
estratégias e os horizontes sociais destas famílias. Uma matéria complexa, até porque estamos face a um grupo que não era socialmente homogéneo. Integravam-no alguns cavaleiros, um grupo compósito de escudeiros, de origens muitos diversa - o mais significativo em termos numéricos - a que se juntavam alguns, poucos, mercadores, e outros homens que a partir do aproveitamento das dinâmicas urbanas ou das relações clientelares se foram destacando do comum da população, não se constatando a presença de mesteirais, pelo menos daqueles que estavam ainda diretamente ligados ao mundo do trabalho.

De qualquer modo, e apesar de todas as diferenças que pudessem ter entre si, havia aspetos que uniam estes homens. Todos tinham já atingido um certo patamar de prestígio e de poder, que lhes permitiu a entrada num órgão governativo já bastante elitizado, encontrando-se também, todos eles, em transcurso de processos de reconhecimento e de reforço de posições. Muito embora os patamares em que se encontravam fossem diversos, as lógicas e os mecanismos que puseram em marcha no sentido da consolidação das suas posições não parecem, apesar de tudo, muito diferenciados, sendo que se constatam fenómenos de mimetismo social, por parte dos grupos de posição inferior face aos da primeira linha concelhia, constituída por cavaleiros e escudeiros.

Uma primeira análise permitiu, desde logo, evidenciar a importância que a afirmação no contexto urbano assumiu para estas famílias, seja no controlo da economia e no enriquecimento que ela permitia, seja nas instituições citadinas. Ficou também claro que as suas lógicas de controlo do poder urbano não se cingiam ao concelho, alargando-se a outras instituições, que contaram na sua afirmação e no seu protagonismo. Para além da relevância que assumiram nas confrarias e em outras pequenas instituições citadinas, muitas destas famílias surgem também ligadas à catedral. Um relevantíssimo polo de poder que não ficou à margem das suas estratégias. A presença dos apelidos das famílias ligadas à governação entre os dignitários e os cónegos da Sé, e mesmo entre os que foram capazes de delinear relevantes carreiras eclesiásticas, como foi o caso dos Oliveira ou dos Brito, não deixa muitas dúvidas quanto à importância que a aproximação às estruturas religiosas assumiu para estas famílias. Importância que, no caso de Évora, foi potenciada pelo facto de a cidade ser sede episcopal. 
Num contexto de forte instabilidade, como foi aquele que se viveu durante uma boa parte do período em estudo, a guerra assumiu para estas famílias um papel crucial nas suas trajetórias. Para alguns, o envolvimento que tiveram nas ações militares constituiu a pedra de toque dos seus processos ascensionais. Assim aconteceu com os Lobo ou com os d'Arca. Famílias oriundas da vilania que, graças ao papel que tiveram ao serviço da causa de Avis, obtiveram a entrada no seio dos grupos nobiliárquicos. Embora de uma forma não tão evidente, esses processos não deixaram de se mostrar relevantes para diversas outras famílias ligadas à governação. Deve dizer-se que o seu envolvimento nas ações bélicas não terminou com Aljubarrota. Manteve-se nos anos que se seguiram e que foram ainda de instabilidade militar, transferindo-se, posteriormente, para os palcos de guerra marroquinos, onde diversos membros das famílias eborenses estiveram presentes. Como é o caso dos Lobo, dos d’Arca, dos Arnalho, dos Tisnado, entre outros. A valorização da função guerreira, enquanto vetor de promoção, conjuga-se também com a forte apetência que mostraram pelas Ordens religiosas e militares, sobretudo as de Santiago e de Avis, nas quais, como já Luís Filipe Oliveira havia demonstrado, se contam muitos dos apelidos que temos na governação municipal.

Contudo, numa cidade, como Évora, onde era forte a interação com os círculos cortesãos, a aproximação à Coroa e ao serviço régio assumiu-se como uma lógica estruturante nos processos ascensionais. A burocracia central e periférica, os cargos militares, a integração entre os escudeiros do monarca e dos infantes assumiram-se como um desiderato e como um objetivo que muitos perseguiram, já que constituíam a via mais segura de entrada ou de reforço de posições no seio dos grupos nobiliárquicos, que constituíam o horizonte social de muitos.

Com efeito, a sondagem que fizemos aos comportamentos e às práticas sociais deixa evidente a adesão das famílias eborenses da primeira linha aos valores comuns dos grupos nobiliárquicos, visíveis, por exemplo, nos esforços tendentes à organização das parentelas - de que a adoção dos apelidos é um claro indício - na defesa e organização dos patrimónios, por via da instituição de morgadios e capelas, ou nas práticas simbólicas, também elas decalcadas dos grupos nobres. 
Para muitos destes homens e famílias da oligarquia, o controlo do poder municipal, que ao longo do nosso período foi estando progressivamente mais eivado das lógicas da coroa, perspetivava-se como uma plataforma de acesso e de aproximação ao serviço régio, que constituía a via mais segura para obter a nobilitação. É em boa parte a importância que os homens ligados ao poder municipal conferiam a estas lógicas que justificam o nosso título: Governar a cidade e servir o rei, duas dimensões incontornáveis das suas estratégias.

Estas são algumas das principais conclusões do estudo que brevemente apresentamos. Trata-se de um estudo de caso, centrado num período temporal específico, cujas conclusões devem ser testadas num tempo mais longo e confrontadas com o que se verificava com outras realidades. O cotejo que fizemos deixa evidente as similitudes com Lisboa, sendo possível que alguns dos traços caraterizadores dos dirigentes eborenses e dos seus modos de funcionamento ocorressem também em outros núcleos urbanos igualmente marcados pela coroa. Para terminarmos, resta dizer que este é apenas um contributo para o esclarecimento de muitas questões que ainda permanecem em aberto quando se reflete sobre a constituição, os comportamentos e as carreiras das elites políticas no Portugal de final da Idade Média.

\section{COMO CITAR ESTE ARTIGO}

\section{Referência electrónica:}

SERRA, Joaquim Bastos - "Apresentação de tese: Governar a cidade e servir o rei. A oligarquia concelhia de Évora em tempos medievais (1367-1433). Tese de Doutoramento em História apresentada à Universidade de Évora, Janeiro de 2016. Orientação da Professora Doutora Hermínia Vilar”.

Medievalista [Em linha]. N. 20 (Julho - Dezembro 2016). [Consultado dd.mm.aaaa].

Disponível em http://www2.fcsh.unl.pt/iem/medievalista/MEDIEVALISTA20/serra2010.html ISSN 1646-740X. 


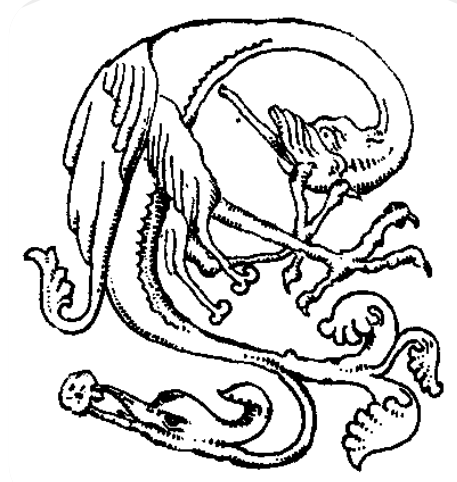

Medievalista online № 20 | Julho - Dezembro 2016 ( ) IEM - Instituto de Estudos Medievais 16 www2.fcsh.unl.pt/iem/medievalista 